\title{
Respon Emosional Orang Tua Dalam Merawat Anak Dengan Kanker Dalam Kondisi Perawatan Palliatif
}

\author{
Rina Mariyana $^{a}$, Allenidekania $^{b}$, Nani Nurhaeni ${ }^{b}$ \\ aProgram Studi Pendidikan Ners, STikes Fort de Kock, Bukittinggi, 26129, Indonesia \\ ${ }^{b}$ Fakultas Keperawatan, Universitas indonesia, Jakarta, 16424, Indonesia \\ e-mail korespondensi: rinamariyana89@gmail.com
}

\begin{abstract}
Cancer is one of the main causes of morbidity and mortality in the world. In caring for children with cancer, parents experienced many changes from this disease where parents feel giving up, feel emotional, and lack of communication between parents and the palliative team can influence the plan for palliative care in children. This study aims to explore the parents' emotional response in caring for children with cancer under palliative care condition. The study was conducted at Jakarta, Bogor, and Bekasi. The research applied descriptive qualitative phenomenology design. Parents caring for children with cancer under palliative care were in-depth interviewed with open-ended questions. Data were then analyzed using the Colaizzi method. This study produced a theme. Anger, effort to distract their anger, exspression the anger, powerlessness. This study shows that during palliative care, parents experience a variety of emotional responses that they cannot control. Therefore, nurses are very important to provide an assessment and facilitate the fulfillment of needs that involve family members and religious experts to control the emotional response caused by the mother
\end{abstract}

Keywords: cancer, parents, emotional, palliative care

\begin{abstract}
Abstrak
Kanker merupakan salah satu penyebab utama morbiditas dan mortalitas di seluruh dunia. Dalam merawat anak dengan kanker orang tua mengalami berbagai perubahan dimana orang tua mengalami keputusasaan, perasaan emosional, serta komunikasi dan koordinasi yang kurang antara orang tua dan tim paliatif, dapat mempengaruhi rencana perawatan paliatif pada anak. Penelitian ini bertujuan untuk mengeksplorasi respon orang tua dalam merawat anak-anak dengan kanker dalam kondisi perawatan paliatif. Penelitian ini menggunakan desain fenomenologi deskriptif. Penelitian dilakukan di Jakarta, Bogor, dan Bekasi. Orang tua yang merawat anak mereka dengan kanker yang menjalani perawatan paliatif diwawancara mendalam dengan pertanyaan terbuka. Data kemudian dianalisis menggunakan metode Colaizzi. Penelitian ini menghasilkan tema, yaitu ekspresi marah, mengalihkan marah, melepaskan marah, ketidakberdayaan. Penelitian ini menunjukkan bahwa selama perawatan paliatif, orang tua mengalami berbagai respon emosional yang tidak sengaja dan tidak bisa mereka kendalikan. Oleh karena itu, perawat sangat penting untuk memberikan penilaian dan memfasilitasi pemenuhan kebutuhan yang melibatkan anggota keluarga serta ahli agama untuk mengontrol respon emosional yang dirasakan orang tua.
\end{abstract}

Kata kunci: kanker, orang tua, emosi, perawatan paliatif

\section{PENDAHULUAN}

Kanker merupakan penyebab utama kematian pada anak di seluruh dunia (van, d. S., Vos, J., van Uden-Kraan, C.,F., Breitbart, W., Rob, A. E. M. T., Cuijpers, P., \& Verdonck-de Leeuw, I.,M, 2013).
Kanker merupakan keganasan mutasi gen yang bersifat genetik (Holmes, Vandenberg, McClarin, \& Dabney, 2016). Berdasarkan Data International Agency for Research on Cancer ([IARC], 2015), pada 
NERS: Jurnal Keperawatan, Volume 14, No. 2, Oktober 2018, (Hal. 55-63)

tahun 2012 angka kejadian kanker pada anak mencapai 14.067.894 di seluruh dunia. Cancer World Report ([CWR], 2017) menyatakan bahwa kanker pada anak meningkat hingga $70 \%$, dari data tersebut angka kematian pada anak kanker mencapai 8,8 juta jiwa.

Berdasarkan hasil statistik di Amerika Serikat memperkirakan bahwa sekitar 10.700 anak akan terdiagnosa dengan kanker (American Cancer Society, 2010). National Cancer Institute (2015) memperlihatkan peningkatan jumlah anak penderita kanker sebanyak $0,6 \%$ per tahun sejak kurun waktu 2007 - 2015.

Angka kejadian kanker pada anak di Indonesia setiap tahun terus meningkat menunjukkan 100.000 anak. Data kanker anak di Jakarta mencapai estimasi 19.000 kasus diperkirakan naik menjadi 14 juta dengan 8,2 juta di antaranya meninggal dunia (Kementerian Kesehatan Republik Indonesia, 2015).

Insiden dan jenis keganasan akibat penyakit kanker pada anak bervariasi sesuai dengan tingat usia, dengan puncak dalam 5 tahun pertama kehidupan dan insiden yang lebih rendah pada mereka yang berusia 8-10 tahun (Yifru \& Muluye, 2015).

Dalam kurun waktu lima tahun ini penyakit kanker pada anak terbanyak adalah leukemia. Data kejadian leukemia pada anak mencapai $54 \%$. Pada tahun 2010-2013 leukemia merupakan jumlah kasus kematian terbanyak di rumah sakit darmais. Diagnosa lain yang dialami anak dengan Limfoma $15 \%$, Wimls Tumor $2 \%$,
Retinoblastoma $9 \% \quad$ (Kementrian

Kesehatan RI, 2015).

Perlu deteksi dini pada orang tua dalam mencegah penyakit kanker. Dimana pada usia anak-anak dengan kondisi ceria dan masa bermain namun pada penyakit kanker anak mengalami berbagai respon baik secara fisik maupun psikologis. Masalah keperawatan yang sering timbul pada anak dengan penyakit kanker diantaranya adalah nyeri, masalah nutrisi, kelemahan, mual, muntah, infeksi, dan hipertermi. Berbagai gejala yang ditimbulkan anak dan sering dikeluhkan oleh anak saat menjalani perawatan. Dimana dunia keperawatan saat ini menfokuskan anak pada fase perawatan palliatif. Perawatan palliatif yang dijalani anak selama menjalani prosedur perawatan baik di rumah sakit maupun dirumah (Deandrea, Montanari, Moja \& Apolone, 2008).

Perawatan paliatif merupakan bagian dari perawatan pasien kanker, terapi yang realistis pada mereka adalah menghilangkan berbagai keluhan yang dirasakan anak (Rasjidi, 2010).

Perawatan paliatif didasarkan pada masalah dan perasaan yang berhubungan dengan stres individu dalam mengatasi penyakit yang dihadapi (Thomsen, Rydahlhansen \& Wagner, 2010). Perawatan paliatif dilakukan pada anak yang mengalami penyakit yang mengancam jiwa dengan memproritaskan peningkatan kualitas hidup dan mengurangi penderitaan (Thomsen et. al., 2010).

Pada perawatan ini ditawarkan lebih awal mengenai identifikasi, penilaian penyakit dan masalah yang dihadapi anak baik fisik, 
psikologi dan rohani (WHO, 2002).

Berbagai keluhan/masalah yang tidak teratasi pada anak kanker akan dapat mempengaruhi kualitas hidupnya, lambatnya penyembuhan luka, kecemasan, gangguan tidur, regresi perkembangan, dan penurunan imun (Aass et. al., 2009; Bowden \& Greenberg, 2014).

Pada perawatan paliatif ini tidak semua orang tua memahami semua fase yang harus mereka lakukan baik ketika anak kesakitan, lemah dan keluhan lainnya. Dimana ketika menjalani perawatan anak menunjukkan berbagai prilaku yaitu prilaku secara verbal (berteriak, meminta bantuan dan mengerang) dan perilaku nonverbal (memegang atau memijat daerah yang menyakitkan, meringis) (Mcpherson et. al., 2013).

Perilaku demikian tergantung pada umur anak dan tingkat perkembangan. Di saat keluhan yang muncul tersebut orangtua merasakan berbagai respon emosional yang akan mempengaruhi kondisi orang tua dalam merawat anak. Keluhan yang ditimbulkan anak dapat diatasi saat anak menjalani perawatan palliatif (Jibb et al., 2015).

Perawatan paliatif dimulai sejak terdiagnosa penyakit sampai akhir kehidupan (Kars, Grypdonck, de KorteVerhoef, Kamps, \& Esther 2011). Anak dan orang tua menjadi lebih kooperatif selama tindakan pengobatan (Lu Jusegren, 2011). Perawatan paliatif ini melibatkan keluarga, dokter dan tenaga perawat (Morrison, \& Meier, 2004).

Sementara keterlibatan orang tua sangat diperlukan dalam merawat anak dengan penyakit kanker (Palermo, 2012). Kiana, Fatemeh, dan Mostafa (2016) menemukan bahwa orang tua mengalami respon emosional yang susah untuk dikontrol saat anak mengeluhkan berbagai reaksi, yang membuat orang tua merasa putus asa dan terpukul saat merawat anak dalam kondisi paliatif.

Dalam perawatan paliatif pada anak belum ada penelitian terkait dengan respon yang ditimbulkan orang tua saat merawat anak kanker, oleh karena itu perlu dilakukan eksplorasi secara lebih mendalam mengenai respon orang tua dalam merawat anak kanker yang menjalani perawatan paliatif. Tujuan penelitian ini adalah untuk menggali respon emosional dari orang tua dalam merawat anak yang menjalani perawatan paliatif

\section{METODE}

Desain penelitian yang digunakan adalah kualitatif dengan pendekatan fenomenologi deskriptif. Pengambilan sampel menggunakan teknik snowball sampling. Dengan jumlah partisipan sebanyak 9 orang tua yang terlibat dalam merawat anak dengan kondisi paliatif. Untuk mendapatkan data yang optimal peneliti melakukan saturasi data dengan melakukan variasi data dari segi umur, tingkat pendidikan orang tua dan diagnosa penyakit yang dialami anak. Penelitian ini dilakukan di wilayah Jakarta namun pengambilan data dilakukan di tempat yang telah disepakati bersama antara partisipan dengan peneliti. Pengumpulan data dilakukan dengan wawancara semi berstruktur yang direkam dengan Sony Voice Recorder dan membuat catatan lapangan untuk mencatat respon non verbal selama wawancara. Analisis data menggunakan metode Colaizzi (1978) 
NERS: Jurnal Keperawatan, Volume 14, No. 2, Oktober 2018, (Hal. 55-63)

dalam Speziale dan Carpenter (2007);

\section{HASIL}

Burns dan Groove (2009).

Uji etik telah dilakukan di Komite Etik Penelitian Kesehatan Fakultas

Keperawatan Universitas Indonesia dengan Nomor surat no. 196/ UN2. F12.D/HKP. 02. 04/ 2017 dengan menilai anonimity dan confidentiality, nonmaleficience, privacy dan dignity, otonomy, beneficience, dan

Karakteristik Anak dari Partisipan

Partisipan yang dilibatkan dalam penelitian ini yaitu orang tua yang memiliki anak kanker yang menjalani perawatan paliatif berjumlah 9 partisipan. Karakteristik partisipan digambarkan dalam bentuk tabel berikut ini: justice. (Maleong, 2007).

Tabel 1.1 Karakteristik Anak dari Partisipan

\begin{tabular}{lllllllll}
\hline P & Usia & Pendidikan & Anak & Usia & JK & Diagnosa Kanker & $\begin{array}{c}\text { Mulai } \\
\text { Terdiagn } \\
\text { osa }\end{array}$ & $\begin{array}{c}\text { Hidup/ } \\
\text { Mening } \\
\text { gal }\end{array}$ \\
\hline P1 & 36 tahun & SMA & An. A & 18 tahun & L & Osteosarcoma & 2001 & $\mathrm{H}$ \\
\hline P2 & 35 tahun & SMP & An. T & 16 tahun & L & Ewingsarcoma & 2015 & $\mathrm{H}$ \\
\hline P3 & 50 tahun & SMA & An. H & 8 tahun & L & Osteosarcoma & 2015 & M \\
\hline P4 & 52 tahun & SMA & An. V & 6 tahun & P & Leukemia & 2004 & M \\
\hline P5 & 33 tahun & SMK & An. F & 10 tahun & L & LLA & 2014 & $\mathrm{H}$ \\
\hline P6 & 42 tahun & SMK & An. S & 7 tahun & P & Retinoblastoma & 2014 & $\mathrm{H}$ \\
\hline P7 & 32 tahun & SMA & An. Ra & 6 tahun & L & Rhabdomyosarcoma & 2008 & M \\
\hline P8 & 42 tahun & SMEA & An. SE & 6 tahun & L & All Osteoporosis & 2016 & $\mathrm{H}$ \\
\hline P9 & 50 tahun & SMA & An. D & 19 tahun & L & Kanker Tulang & 2012 & M \\
\hline
\end{tabular}

\section{Ekspresi Marah}

Saat merawat anak dengan kondisi sekarat orang tua selalu berupaya untuk memberikan semua yang terbaik bagi anak mereka. Saat menghadapi anak dengan kondisi sakit yang memvonis bahwa umur anak mereka tidak lama lagi, hal ini membuat perasaan orang tua yang tidak menentu, seringkali orang tua memunculkan respon emosional saat berhadapan dengan anak mereka yang akan berpengaruh pada psikologis anak mereka sendiri. Orang tua selalu berupaya sekuat tenaga agar tidak meluapkan emosi kepada anak mereka namun terkadang emosi itu timbul tanpa mereka sadari.
Saya sedih melihat anak saya seperti itu..... (p7)

Tidak... saya sudah tidak bekerja lagi, saya marah sama diri saya sendiri ya........ (P1)

Berhari hari saya tidak makan, tidak ngapa-ngapain saya.....diam saja. (P3)

Perasaan marah orang tua jika tidak bisa merawat anak, hal ini di ungkapkan oleh beberapa partisipan antara lain:

"saya suka marah marah nama nya itu ya saya gak ngerasain sakit.... Saya suka marah... (p3) 
NERS: Jurnal Keperawatan, Volume 14, No. 2, Oktober 2018, (Hal. 55-63)

"saya marah juga sama allah gitu, saya

kurang apa sich, gitu kan saya sudah sedekah sudah apa tapi anak saya kena sakit padahal banyak yang jahat yang koruptor lah apa anak dia gak ini ,, tapi anak ku yang dia bersih gak makan apa apa... (p7)

"kenapa dia sakit sakit kanker dan dia udah meninggal pun saya merasa marah sama allah saya sudah abis abisan kenapa ambil lagi anak $k u(p 5)$

"ya kadang suka marah, karena cerewet nya, itu belum beres itu belum beres,,, “ (p2)

"Malam malam dia pengen keluar saya gotong gotong ama kayak saya di bawa kesal sama dia (P3)

Kadang ya kesal juga cuma gimana...

\section{Melepaskan kemarahan}

Orang tua terkadang berantem dengan ibu mereka sendiri yang mana dibilang mereka terlalu memanjakan anak mereka. Padahal itu mereka lakukan hanya untuk membuat anak nya bahagia di sisa hidup nya

"mama ngerti gak sich ma saya sakit saya capek ngerti gak sich ma. Aku juga susah ngurusin kamu itu kan jadi akhirnya berantem sama anak (p4)

Bertengkar dengan saudara saya yang lain ,orang tua saya juga,, tapi saya tutupi dari anak... (P9)

Ibu saya bilang saya terlalu memanjakan $S$, saya sering bertengkar di situ,,,, (P9)

Ga ada ...paling ya ibu rumah tangga aja. Sebenernya pengen begitu...gitu...cuman ga bisa. Kadang bertengkar dengan ayah nya..... (p2)

Orang tua meluapkan emosi yang mereka rasakan dengan menangis, pasrah dan terpukul

Jadi dokter nyatakan ga boleh gitu...ee..udah la kemo, keluarga juga sepakat ga usah kemo lagi, kita pasrah aja gitu kan.....

"dia orang nya teriak-teriak ya, mengeluh itu trus saya pun berusaha mengendalikan tidak marah, kadang ujungnya marah juga (P2)

Saat kakak akan operasi di situ saya langsung nangis sejadi-jadinya, saya emosi pada diri saya sendiri .....(P4)

\section{Mengalihkan marah}

Orang tua tidak tahu menceritakan kepada siapa atas penderitaan yang mereka alami, yang mengakibatkan mereka meluapkan emosi dengan cara mereka

Kadang saya mondar mandir jalan sendiri, anak saya tidak saya ajak, saya jalan jauh sampai capek...... (P8)

Saya pergi ke tetangga rumah untuk menghilangkan marah

Gak ada kadang nonton tv ,, jadi kalau ada yang lucu bisa ketawa sendiri ...... (p1)

Saya bingung cerita ke saudara sudah tidak peduli mereka, suami saya juga meninggalkan saya....... (p9)

\section{Ketidakberdayaan}

"ada sich jenuh nya juga, terpukul, sekarang tadi nya saya biasa kerja jadi 
NERS: Jurnal Keperawatan, Volume 14, No. 2, Oktober 2018, (Hal. 55-63)

gak kerja jenuh nya ya, jenuh juga awalnya monoton ,,, “ (p8)

" manusia udah ada titik jenuh, udah ada titik dimana bosan,,, tapi semua itu yang saya rasakan tapi saya tetap fokus ke $R$ kan " (p7)

Dalam perawatan paliatif orang tua merawat anak di rumah dengan kondisi tersebut orang tua merasa kebingungan karena merawat anak sendiri di rumah tanpa ada keluarga yang mengerti tentang kesehatan hal ini diungkapkan oleh orang tua

Kalau kita udah eee udah kasih...dibujuk ini itu ga mau...udah salah satu jalannya udah di infus dek, disitu saya jadi bingung.... (P8)

Dokter mengangkat mata anak saya saya miris, disitu saya tidak berdaya ..orang tua mana yang tega melihat anaknya tampa mata... bingung juga harus di apakan ...(P6)

\section{PEMBAHASAN}

Pada penelitian ini menggambarkan bahwa Ibu mengalami berbagai prilaku akibat penyakit yang dialami anak, dimana anak menjalani pengobatan dalam jangka panjang. Selama anak menjalani perawatan orang tua meluapkan berbagai respon emosional yang tidak pernah disadari.

Pada penelitian ini dilihat lebih spesifik mengenai respon emosional yang ditimbulkan oleh ibu saat ibu merawat anak yang menjalani perawatan paliatif. Berbagai respon emosional orang tua muncul saat ibu merawat anaknya, ekspresi emosi yang dimunculkan orang tua dimana orang tua merasa sedih dengan kondisi yang dialami anak nya, orang tua menarik diri dari pekerjaan nya, orang tua menjadi murung dan sering. Sejalan dengan penelitian yang dilakukan oleh Ljungman, L., Cernvall, M., Ghaderi, A., Ljungman, G., Louise, v. E., \& Ljótsson, B. (2018) bahwa orang tua mengalami kesedihan yang mendalam, cemas dan depresi dalam menyelesaikan pengobatan yang dilakukan oleh anak.

Pada penelitian ini menggambarkan cara orang tua dalam melepaskan marah yang mereka alami dengan sering beradu argumen dengan ayah ibu, dengan suami bahkan ke anak mereka sendiri . Beberapa partisipan selalu beradu argumen saat anak sakit, argumen yang timbul baik dari anak saat anak tidak mau melakukan kemoterapi, Argumen antara ibu dan anak juga muncul saat anak tidak mau meminum obat. Beradu argumen dengan ayah dan anggota keluarga lainnya terkait pengobatan yang tepat yang akan diberikan kepada anak mereka. Ibu dan ayah sering berbeda pendapat dengan anggota keluarga yang lain saat panik melihat anak kesakitan. Sejalan dengan penelitian Clarke (Young et al., 2002) yang mengungkapkan orangtua berusaha mengatur emosi yang ditimbulkan oleh orang tua dalam upaya pengobatan yang dijalani (Kissil, K., Niño, A., Ingram, M., \& Davey, M, 2014).

Berdasarkan penelitian yang dilakukan diperoleh data bahwa orang tua melampiaskan marah dan kesal kepada anggota keluarga lain namun berupaya supaya anak tidak merasakan kemarahan yang mereka rasakan. Dari penelitian orang tua mengalihkan marah dengan menonton tv, ke rumah tetangg untuk 
sekedar bercerita, dan bahkan ada yang berjalan sendiri tanpa ada tujuan yang jelas. Sejalan dengan Bougea, A., Darviri, C., \& Alexopoulos, E. C. (2011) penelitian yang dilakukan oleh orang tua melakukan terapi pijat untuk membebaskan rasa cemas yang di timbulkan akibat penyakit yang diderita oleh anak mereka. Keluarga mengalami kecemasan dan depresi rendah berkaitan dengan diagnosa yang dialami oleh anak mereka Inhestern, L., Beierlein, V., Bultmann, J. C., Moller, B., Romer, G., Koch, U., \& Bergelt, C. (2017)

Berdasarkan penelitian yang didapat orang tua bahkan menangis dan sangat terpukul sekali saat anak menjalani operasi dan ada beberapa responden yang merasa tak berdaya ketika mata anak nya harus diangkat dan digantikan dengan mata palsu. Orang tua tidak dapat berbuat apaapa saat anak mereka kesakitan, saat anak mereka berjuang melawan penyakit yang mereka rasakan. Rasa tak berdaya juga ditunjukkan orang tua saat merawat anak dengan berbagai keluhan yang muncul.

Anak mereka harus menjalani prosedur yang menyakitkan. Hal tersebut membuat orang tua merasakan tidak berdaya, orang tua beranggapan betapa berat cobaan yang anak mereka hadapi (McGrath, 2001). Berdasarkan penelitian yang dilakukan didapatkan bahwa Orang tua berfikir bahwa ia lebih ikhlas jika seandainya sakit yang dirasakan oleh anak mereka dapat berpindah ke diri mereka. Penelitian Kohlsdorf, \& Costa Junior, (2012) mengatakan bahwa ayah dan ibu berbeda tuntutan dalam merawat anak dimana mereka cenderung menghadapi tantangan yang berbeda

\section{KESIMPULAN DAN SARAN}

Orang tua meluapkan segala emosi yang dirasakan namun hal tersebut tidak di ungkapkan saat orang tua berada di dekat anak. Perawat sangat penting untuk menilai secara berkelanjutan dari kebutuhan emosional yang dialami orang tua dan memfasilitasi pemenuhan kebutuhan spiritual yang melibatkan keluarga dan tokoh agama. Perawat dapat memfasilitasi kegiatan yang dapat digunakan orang tua dalam mengontrol setiap respon yang akan muncul. Perlu dilakukan penelitian yang terkait dengan peningkatan kualitas hidup anak terhadap perawatan paliatif. Peneliti selanjutnya dapat mengkaji hal yang dapat dilakukan oleh perawat dalam mengelola respon emosi yang ditimbulkan orang tua.

\section{UCAPAN TERIMA KASIH}

Ucapan terima kasih disampaikan kepada seluruh orang tua yang telah bersedia menjadi responden dan membantu dalam proses penelitian.

\section{DAFTAR PUSTAKA}

American Society for Pain Management Nursing, Emergency Nurses Association, American College of Emergency Physicians et al. (2009). Optimizing the treatment of pain in patients with acute presentations. Retrieved from http:www.aspmn.org/Organization/d ocuments/OptimizingPositionPaper.p df.

Bougea, A., Darviri, C., \& Alexopoulos, E. C. (2011). A systematic review of randomized controlled interventions for parents' distress in pediatric leukemia. ISRN Oncology, Retrieved from 
NERS: Jurnal Keperawatan, Volume 14, No. 2, Oktober 2018, (Hal. 55-63)

https://search.proquest.com/docvie w/922823661 ?accountid $=38628$

Deandrea, M., Montanari, L., Moja, G., \& Apolone. (2008). Prevalence of undertreatment in cancer pain. A review of published literature. Ann Oncol 2008; 19 (12): 1985-1991. doi: 10.1093/annonc/mdn419

Holmes, L.,Jr, Vandenberg, J., McClarin, L., \& Dabney, K. (2016). Epidemiologic, racial and healthographic mapping of delaware pediatric cancer: 20042014. International Journal of Environmental Research and Public Health, 13(1), 1-14. doi:http://dx.doi.org/10.3390/ijerp h13010049

Inhestern, L., Beierlein, V., Bultmann, J. C., Moller, B., Romer, G., Koch, U., \& Bergelt, C. (2017). Anxiety and depression in working-age cancer survivors: A register-based study. BMC

Cancer, 17doi:http://dx.doi.org/10 .1186/s12885-017-3347-9

Kars, M. C., Grypdonck, M. H., F., de Korte-Verhoef, M.,C., Kamps, W. A., Meijer-van den Bergh, Esther M. (2011). Parental experience at the end-of-life in children with cancer: 'preservation' and 'letting go' in relation to loss. Supportive Care in Cancer, 19(1), 27-35. doi:http://dx.doi.org/10.1007/s005 20-009-0785-1

Kiana, B., Fatemeh, A., and Mostafa, K. (2016). "Effect of Mother's Voice on Postoperative Pain Pediatric in Tonsillectomy Surgery," Journal of Pediatric Nursing, vol. 3, no. 2, pp. 51-57, 2016. View at
Publisher - View at Google Scholar

Kissil, K., Niño, A., Ingram, M., \& Davey, M. (2014). "I knew from day one that i'm either gonna fight this thing or be defeated": African american parents' experiences of coping with breast cancer. Journal of Family Nursing, 20(1), 98-119. doi:http://dx.doi.org/10.1177/1074 840713504035

McPherson, C. J.,R.N.PhD., Hadjistavropoulos, T.,PhD.R.D.Psych, Lobchuk, M. M.,R.N.PhD., \& Kilgour, K. N.,R.N.M.ScN.PhD.(c. (2013). Cancer-related pain in older adults receiving palliative care: Patient and family caregiver perspectives on the experience of pain/Les douleurs liées au cancer chez les personnes âgées en soins palliatifs : Le point de vue des patients et des familles sur l'expérience de la douleur. Pain Research \& Management : The Journal of the Canadian Pain Society, 18(6), 293-300. Retrieved from

https://search.proquest.com/docvie w/1497176366 accountid $=25704$

Morrison, R. S., \& Meier, D. E., M.D. (2004). Palliative care. The New England Journal of Medicine, 350(25), 2582-90. Retrieved from https://search.proquest.com/docvie $\underline{w} / 223942911$ ?accountid $=25704$

Palermo, T. M., \& Karlson, C. W. (2015). Developmental Perspective Family, $\quad$ 69(2), 142-152. 
NERS: Jurnal Keperawatan, Volume 14, No. 2, Oktober 2018, (Hal. 55-63)

http://doi.org/10.1037/a0035216.

Rasjidi, I. (2010). Perawatan Paliatif

Suportif dan Bebas nyeri pada

Kanker. Sagung Seto:Jakarta

Thomsen, T. G., Rydahl-hansen, S. and Wagner, L. (2010) 'A review of potential factors relevant to coping in patients with advanced cancer', pp. 3410-3426. doi: $10.1111 / \mathrm{j} .1365-$

2702.2009.03154.x.

van, d. S., Vos, J., van Uden-Kraan, C.,F., Breitbart, W., Rob, A. E. M. T., Cuijpers, P., \& Verdonck-de Leeuw, I.,M. (2013). Meaning making in cancer survivors: A focus group study. $P L o S$ One, 8(9)

doi:http://dx.doi.org/10.1371/jour nal.pone.0076089

World Health Organization (2002) National Cancer Control Programmes: Policies and Managerial Guidelines, 2nd edn. World Health Organization, Geneva.

World Health Organization (WHO). (2015). World health statistics 2013.

www.who.int/gho/.../world health _statistics/EN_WHS2013_Full.pdf

Yifru, S., \& Muluye, D. (2015). Childhood cancer in gondar university hospital, northwest ethiopia. BMC Research Notes, 8 Retrieved from https://search.proquest.com/docv $\underline{\text { iew/1780114845? accountid=386 }}$ $\underline{28}$ 